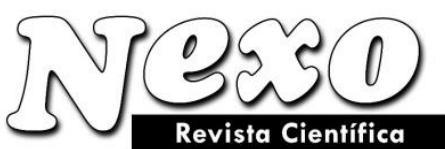

Vol. 36, No. 06, pp. 1667-1676/Diciembre 2021

\title{
State of open wagon body when loading on a rotary car dumper
}

\section{Estado de la carrocería de vagón abierto al cargar en un volquete de coche rotativo}

\author{
Ilya V. Chepurchenko ${ }^{1, *}$, Svetlana V. Korkina ${ }^{2}$ \\ ${ }^{1}$ The Branch of the Samara State Transport University in Nizhny Novgorod, Nizhny Novgorod, Russia. \\ ${ }^{2}$ Samara State Transport University, Samara, Russia. \\ *email: ilya.v.chepurchenko@mail.ru
}

(recibido/received: 12-octubre-2021; aceptado/accepted: 01-diciembre-2021)

\begin{abstract}
The use of modern means of mechanization of loading and unloading operations in places of mass processing of bulky loads in railway and water connection allows to increase the efficiency and productivity of various types of transport, to ensure the safety of load and rolling stock. The most common method of unloading open wagons in ports, mining enterprises, thermal power plants, etc. is the use of special rotary car dumpers. However, it should be noted that unloading on the car dumpers leads to damage of the carriages structural elements. The article presents the results of strength calculations of the car dumper body under the influence of specified dynamic loads from the expiring cargo. They show that the safety margin of the load-bearing elements of the car body is not enough at critical corners of rotation of the car dumper rotor. The studies were carried out using modern computer modeling methods used in the development of newgeneration freight car designs. The software package took into account the effects of dynamic loading as external factors that occur at different corners of the car dumper rotor. The implementation of the results obtained at the design stage of innovative structures of open wagon car bodies will allow predicting the operational parameters of load-bearing structures. The presented studies are aimed at improving the safety and operational reliability of the cargo car fleet.
\end{abstract}

Keywords: Car Dumper; Carriages Design; Dynamic Loads; Open Wagon; Safety Margin; Safety of the Car Fleet.

\section{RESUMEN}

El uso de medios modernos de mecanización de operaciones de carga y descarga en lugares de procesamiento masivo de cargas voluminosas en conexiones ferroviarias y de agua permite aumentar la eficiencia y productividad de varios tipos de transporte, para garantizar la seguridad de la carga y el material rodante. El método más común de descarga de vagones abiertos en puertos, empresas mineras, centrales térmicas, etc. es el uso de volquetes rotativos especiales. Sin embargo, debe tenerse en cuenta que la descarga en los volquetes de los vagones daña los elementos estructurales de los vagones. El artículo presenta los resultados de los cálculos de resistencia de la carrocería del volquete de automóviles bajo la influencia de cargas dinámicas específicas de la carga que expira. Muestran que el margen de seguridad de los elementos de carga de la carrocería del automóvil no es suficiente en las esquinas críticas de rotación del rotor del volquete del automóvil. Los estudios se llevaron a cabo utilizando métodos modernos de 
modelado informático utilizados en el desarrollo de diseños de vagones de mercancías de nueva generación. El paquete de software tuvo en cuenta los efectos de la carga dinámica como factores externos que ocurren en diferentes esquinas del rotor del volquete del automóvil. La implementación de los resultados obtenidos en la etapa de diseño de estructuras innovadoras de carrocerías abiertas permitirá predecir los parámetros operativos de las estructuras portantes. Los estudios presentados tienen como objetivo mejorar la seguridad y confiabilidad operativa de la flota de carros de carga.

Palabras claves: Car Dumper; Diseño de carruajes; Cargas dinámicas; Vagón abierto; Margen de seguridad; Seguridad de la flota de automóviles.

\section{INTRODUCCIÓN}

Currently, at large industrial enterprises of the energy, chemical, mining industry, in river and sea ports, regulatory documents allow unloading bulk cargo exclusively by dumping with the use of special devices stationary car dumpers.

The most common car dumper designs of the following manufacturers: Thyssenkrupp, Heyl \& Patterson, Penzatekhnomash, etc. are used in ports, enterprises of the metallurgical, energy, and chemical industries.

With the undoubted advantage of unloading by the dumping method in comparison with the grab, the result of the expiration of the load is significant damage to the load-bearing elements of the body structure of the unloaded open wagon. The most common are deformations of the top cording, fracture and deformation of the skin, breakage and bending of the struts, etc. (Senderov, y Losev, y Drugal, 1984; Azab et al., 2020). The reasons for these damages are both the impact on the car nodes of the car dumper elements, and the load from the expiring cargo. Moreover, the loads increase when unloading the packed bulk cargo. In addition, there are falling out of the elements of the autoscene device, the leaf springs of the bogie, the check of the brakeblocks. It should also be noted that in the case of unloading by dumping method, the safety of the carriage largely depends on the technical condition of the car dumper elements - the serviceability of the car dumper upper stops and the reinforcement of the stopping plate.

\section{REVIEW OF EXISTING TECHNOLOGIES}

The authors of (Gorfin, 2003) did not consider the dynamic loads acting on the carriage when calculating the rotary car dumper in the process of dumping. In this regard, the calculation schemes given in (Gorfin, 2003 ) were improved and specified. The schemes introduce additional reaction and loading forces acting on the body elements that occur at various stages of the unloading process (Figures 1,2). 


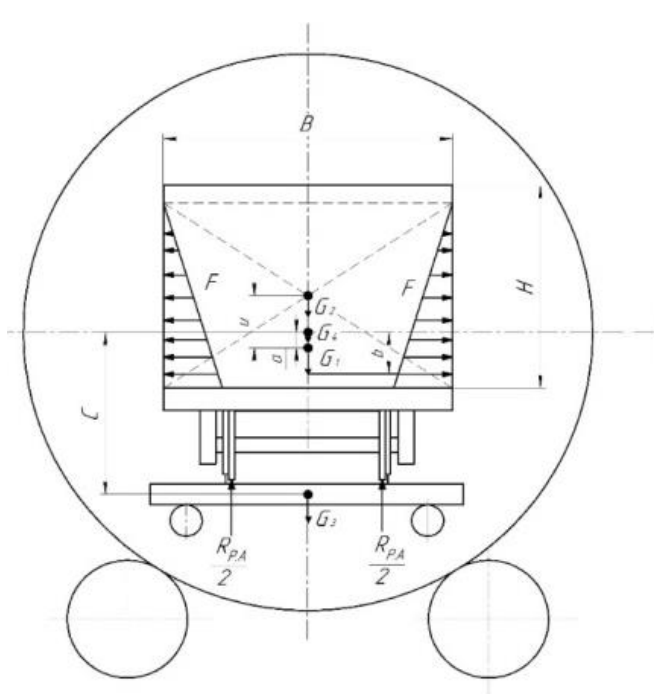

a)

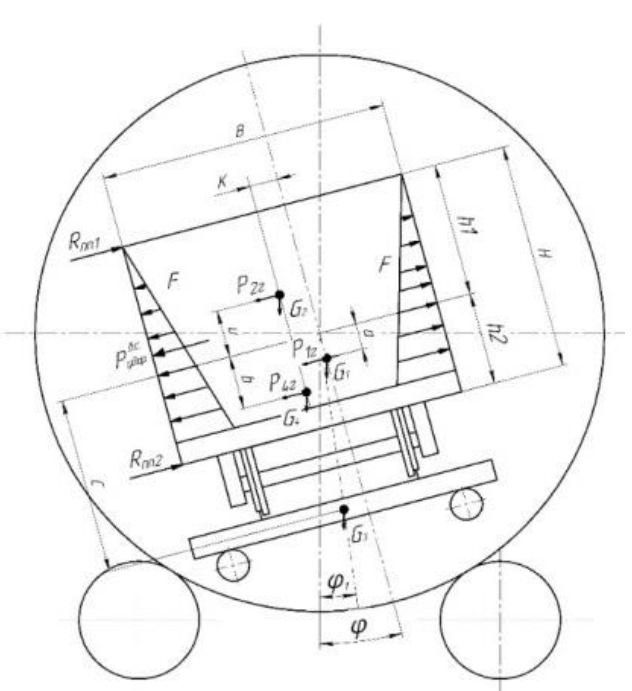

b)

Figure 1. The initial stage of the carriage dumping process during unloading: a) the initial position of the carriage $\left(0^{\circ}\right)$; b) the position of the carriage at the time of contact with the stopping plate $\left(9 \div 16^{\circ}\right): R_{R . R}-$ the reaction force of the rails; $R_{s . p .}$ - the reaction force acting from the side of the stopping plate, resulting from the impact of the body $\left(R_{\text {s.p.1 }}\right.$ и $R_{\text {s.p. } 2}$ - changing reaction forces, which are determined by the degree of unevenness of the suspension of the body' side wall when straightening the leaf springs of suspension); $G_{1}, G_{2}, G_{3}, G_{4}$ - the gravity of the rotor of the car dumper, expiring cargo, cradle of car dumper and open wagon. $H$ - the height of the car body; $B$ - the width of the car body; $F$ - the thrust force resulting from the impact of the load on the side wall of the carriage; $\varphi$ - the angle of rotation of the "car-car dumper" system; $K$ - the displacement of the car dumper cradle in relation to the rotor; $P_{1 g}, P_{2 g}, P_{4 g}$ - horizontal components $G_{1}, G_{2}, G_{4}$, which determine the load from the impact of the side wall of the body on the stopping plate of car dumper, $P_{i m p .}^{\text {s.w. and }} P_{\text {st.1(2) }}^{\text {u.b }}$

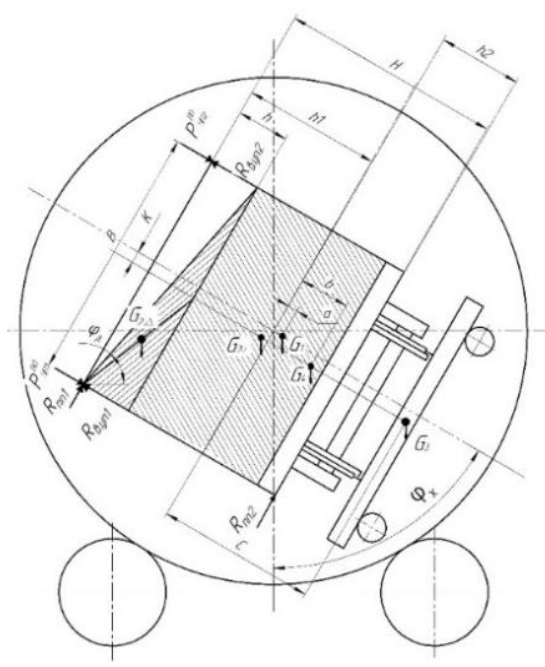

c)

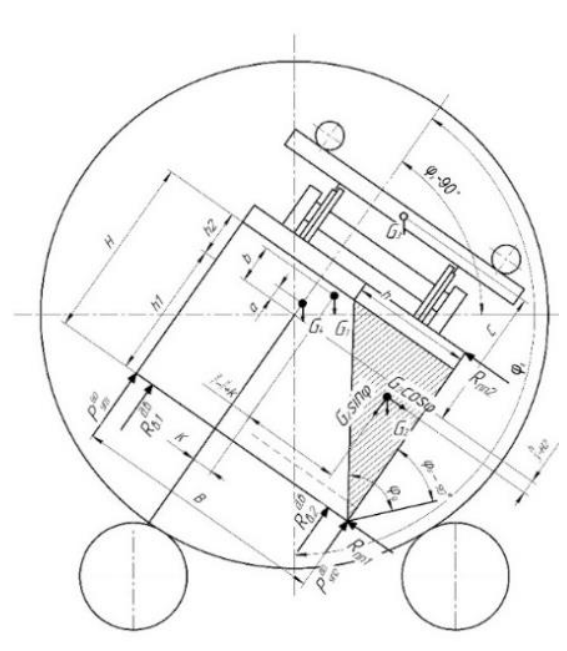

d)

Figure 2. The final stages of unloading: c) the beginning of the load movement, the interaction of the body with the car dumper stops: d) the completion of the tripping process: $R_{U . S T}$ - the reaction force of the stops (the value $R_{U . S T .1}$ and $R_{U . S T .2}$ is determined by the position of the center of the system mass); $\varphi_{x}$ - the angle of rotation of the system "car-car dumper"; $P_{\mathrm{st.1}(2)}^{u . b .}$ - the loading of the top cording, arising from the action of the upper stops; $G_{2 \Delta}$ - the weight of the emptied part of the load; $P_{v 1(2)}^{a . v}$ - the load from the car dumper vibration (170-175 $)$ 
The expiration of the load when using a stationary rotary car dumper begins when the equality of $\varphi_{x} \geq \varphi_{d}$ is reached, i.e. when the angle of rotation becomes equal or greater than the angle of the natural slope of the load (Petrov, et al. 2017; Chepurchenko et al., 2018).

With a change in the corner of rotation, unloading occurs unevenly, the speed of cargo expiration increases with an increase in the angle of dumping. The angle of full discharge of the cargo, according to the experience of the cur dumper operation, is $135^{\circ}-140^{\circ}$. In the case of a frozen or paked cargo, when there is sticking or freezing to the walls of the carriage, the maximum angle of rotation for carriages of $1520 \mathrm{~mm}$ gauge can increase to $180^{\circ}$.

At the beginning of the dumping process, as shown in Figure 1, $a$, the forces acting on the body will be: $F$ - the thrust forces and $G_{2}, G_{4}$-the gravity forces of the load and the body, respectively. During the subsequent rotation, the system "cradle cur dumper-car body" is shifted by a distance of $K$. The carriage is pressed against the side wall of the car dumper when the value of the corner of rotation increases, it grows from 0 to $\varphi_{1}$ (Figure 2,b). The turn of the car dumper cradle occurs with some acceleration, which leads to the impact of the carriage body on the car dumper stopping plate. It is this impact that can lead to the appearance of remaining deformations of the body (skin sheets). The cause of the damage may also be the fact that the side wall of the carriage does not rest on the entire plane of the stopping plate (violation of the geometry of interaction) due to the leaf springs uncompressing of the bogie swing suspension.

Unloading of the carriage begins with the angle of rotation equal to the angle of the natural slope of the bulk cargo. The process of cargo expiration leads to loading of the stopping plate from the carriage body (side wall). The angle $\varphi_{x}$ increases in this case from the value of the angle of the load natural slope in the movement of $\varphi_{d}$ to $\varphi_{2}$ (Figure 1, c). The cross-sectional area of the bulk cargo in the open wagon body is represented as a touching rectangle and triangle.

When the angle of rotor switching of the car dumper reaches a value of $56^{\circ}$, the body top cording is affected by the impact from the front and back cur dumper stops. Further, until the full switching of the cur dumper rotor, the car body remains in the same position.

At the last stage of unloading, the angle of rotation $\varphi_{x}$ increases to the final angle of rotation $\varphi$. The volume of the load is now represented in the form of a triangular prism (cross-section is triangle), as shown in Figure 2 , d. The load-bearing elements of the car structure during the final phase of unloading experience the effects of significant gravity forces $G_{2}, G_{3}, G_{4}$.

Thus, the results of the analysis of the carriage positions when unloading on the car dumper allowed us to conclude that the method (Gorfin, 2003) did not consider the following factors and processes that lead to significant damages of the load-bearing elements of the carriage structure. For example, violation of the geometry of the carriage body interaction with the stopping plate of the car dumper due to the uncompression of the leaf springs of the bogie swing suspension; loads from the weight of the car dumper cradle on the body top cord; additional loads on the body that occur when unloading monolithic (frozen or paked) cargo.

\section{REVIEW OF PUBLICATIONS}

It should be noted that the problem analyzed in the article is not sufficiently studied. For further study and simulation of the dynamic system "wagon-cur dumper" in the software package, the methodology proposed by the authors (Kostek y Aleksandrowicz, 2017), developed for the study of car accident scheme, can be applied. This method allows to determine with a sufficiently high accuracy the impact and static loads from the elements of the car dumper on the load-bearing structure of the car body. 
The developed method (Dižo y Steišunas y Blatnický, 2016) for determining vertical and horizontal accelerations in the "wheel-rail" system allows to use the computer modeling proposed by the authors. The results of calculations using different speeds of the studied unit of rolling stock show the amplitudes of fluctuations in the dynamic system, which also allows to apply such approach in determining the forces acting on the carriage when dumping.

The authors (Chepurnoy, et al. 2017) propose methods for developing and justifying innovative solutions in creating projects for promising oil car designs. The study uses strength criteria, the purpose of the development is to optimize the technical characteristics of the designed structures. The authors conducted comprehensive studies on the compliance of the designed objects with the current standards and the required strength characteristics.

The authors (Gorbunov, et al. 2017) analyzed the obtained theoretical and experimental studies aimed at improving the dynamic characteristics of locomotives. Based on the received in-formation, the authors formulated the tasks of further studies to improve the driving qualities of the locomotive. The calculated schemes of the action of forces shown by the authors allow them to be applied to the solution of the problem of determining the forces and accelerations in the process of the car body dumping.

The importance of studying the performance of mechanized systems for handling transport units in places of mass unloading is reflected in (Scientific Research Institute of Railway Transport, 2016). The proposed approach of integrating a mathematical model in order to minimize the turnover time of cargo units by optimizing technological operations in the seaport. This method allows optimal use of the port infrastructure, including car dumpers (Figure 3), for handling freight cars in order to comply with the technology of unloading cargo and ensure the safety of the car fleet (Nosyrev y Chepurchenko y Korkina, 2018a).

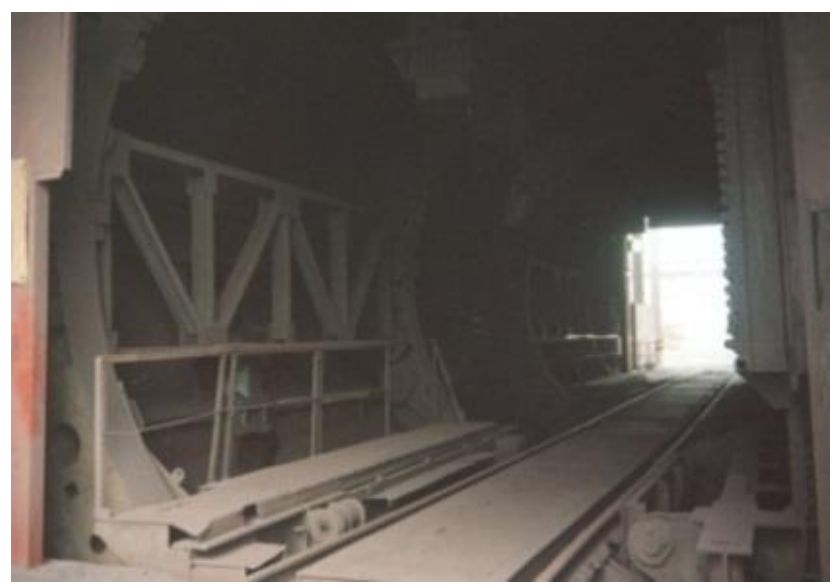

Figure 3. General view of the car dumper

These works do not affect the dynamic process of unloading the carriage on the car dumper, which is accompanied by pressure in the load-bearing elements of the body, which, if the permissible voltage values given in (Nosyrev y Chepurchenko y Korkina, 2018b) are exceeded, can lead to damage of the body.

The forces acting on the car body considered in (Chepurchenko, 2019) were not taken into account in the study of the stress-strain state of carriage, which cannot fully reflect the concentration zones with maximum voltages.

\section{RESULTS}


The process of impact interaction of the car with the cur dumper stopping plate is studied by constructing a finite element model of the body and further modeling the physics of the process. When drawing up the design scheme, kinematic fasteners (restrictions on movements) are introduced.

A system of equations regarding the angles of rotation and displacements of nodal points is compiled, and finite element stiffness matrices are constructed. Determining the displacements of nodes is a problem of finding dependencies under the condition of stationarity of the potential energy function $\sum W_{p}$.

For the body nodes, in accordance with the Ritz method, the displacement fields have the form:

$$
\left.\begin{array}{c}
u=\sum_{i=1}^{n} u_{i} \varphi_{i}(x, y, z) ; \\
v=\sum_{i=1}^{n} v_{i} \psi_{i}(x, y, z) ; \\
\omega=\sum_{i=1}^{n} \omega_{i} \xi_{i}(x, y, z) ;
\end{array}\right\}
$$

where $\varphi_{i}, \psi_{i}, \omega_{i}$-interpolating displacement;

$u_{i}, v_{i}, \omega_{i}$ - node movements, $\mathrm{m}$.

These expressions for the LSC in matrix form are written as:

$$
\left[\begin{array}{l}
u \\
v \\
\omega
\end{array}\right]=L(x, y, z)\left[\begin{array}{c}
\varphi_{i} \\
\psi_{i} \\
\xi_{i}
\end{array}\right]=L(x, y, z) \cdot \vec{\alpha}
$$

where $\vec{\alpha}=\left[\alpha_{1}, \alpha_{2}, \ldots \alpha_{12}\right]^{\mathrm{T}}$ is the transposed matrix of the interpolation polynomials when the equality is achieved $\alpha_{i}=\left[\varphi_{i}, \psi_{i}, \omega_{i}\right]$.

Then the matrix of nodal displacements in the global coordinate system (GSK) has the form:

$$
\vec{Z}=\left[\vec{z}_{1}, \vec{z}_{2}, \vec{z}_{3}, \vec{z}_{4}\right]^{T}
$$

where $\vec{z}_{i}^{T}=\left[\varphi_{i},{ }_{i}, \omega_{i}\right]$ is the vector of the node's movements on the LSK.

After mathematical transformations, the node movement in the GSK is defined as:

$$
\vec{Z}(x y z)=\left[\begin{array}{c}
u \\
v \\
\omega
\end{array}\right]=L(x, y, z) L^{-1} \cdot \vec{z}^{-1},
$$

where $\quad \vec{\alpha}=L^{1} \cdot \vec{Z}$.

In order to determine the stiffness matrix of the entire structure, equations of the form are compiled: 


$$
\left\{\begin{array}{c}
P_{1} \\
P_{2} \\
\vdots \\
P_{P} \\
\vdots \\
P_{m}
\end{array}\right\}=\left[\begin{array}{lllccc}
r_{11} & r_{12} & \cdots & r_{1 p} & \cdots & r_{1 m} \\
r_{12} & r_{22} & \cdots & r_{2 p} & \cdots & r_{2 m} \\
\vdots & \vdots & \vdots \vdots \vdots & \vdots & \vdots \vdots \vdots & \vdots \\
k_{p 1} & k_{p 2} & \cdots & k_{p p} & \cdots & k_{p m} \\
\vdots & \vdots & \vdots \vdots \vdots & \vdots & \vdots \vdots \vdots & \vdots \\
r_{m 1} & r_{m 2} & \cdots & r_{m p} & \cdots & r_{n m}
\end{array}\right] \cdot\left\{\begin{array}{c}
Z_{1} \\
Z_{2} \\
\vdots \\
Z_{p} \\
\vdots \\
Z m
\end{array}\right\}
$$

where $r$-matrix of rigidity of the carriage body structure;

$P$ and $Z$ are nodal forces and displacements, respectively.

The system is solved by the Gauss method. Deformation fields are constructed using the Cauchy formula:

$$
\vec{\varepsilon}=\left[\varepsilon_{x}, \varepsilon_{y}, \varepsilon_{z} ; \gamma_{x y}, \gamma_{y z}, \gamma_{z x}\right]=F=B \cdot L^{-1} \cdot \vec{Z}
$$

where $F$ is the matrix of the Cauchy equations;

$B$ is a differentiated matrix $L(x y z)$;

$\varepsilon, \gamma$ - for nodal points, the relative deformations and rotation angles.

Voltage fields are constructed by the deformation field using Hooke's law:

$$
\vec{\sigma}=D \cdot B \cdot L^{-1} \cdot \vec{Z}
$$

where $D$ is the inverse matrix for the volume stress state.

The design scheme of the body when turning at $56^{\circ}$ has the form shown in Figure 4 .

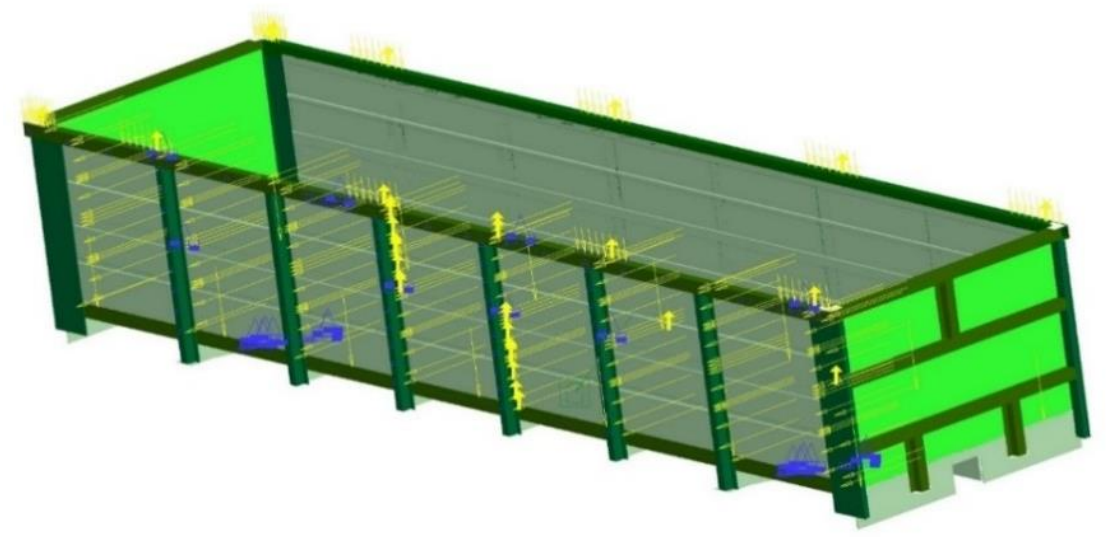

Figure 4. Example of the resulting calculation scheme (when turning $56^{\circ}$ )

Similar diagrams according to the calculation protocols are constructed for other angles of rotation of the car dumper platform.

The analysis of calculations shows that the greatest equivalent stresses occur at different angles of rotation of the platform at the junctions of the body racks with the side wall skin and in the middle and final sections of the body - in the middle part of the skin sheets. 
The graphical dependences of stresses and displacements on the angle of rotation of the system obtained from the calculations of the mathematical model of the unloading process (Figures 5-8) show that the greatest stresses in the side wall reach $853 \mathrm{MPa}$ (with an acceptable 275-295 MPa) at the moment when the angle of rotation of the platform reaches $90^{\circ}$. The greatest values of displacement reach $76 \mathrm{~mm}$, also when turning by $90^{\circ}$. Increasing the angle of rotation will cause the body structure deformation.

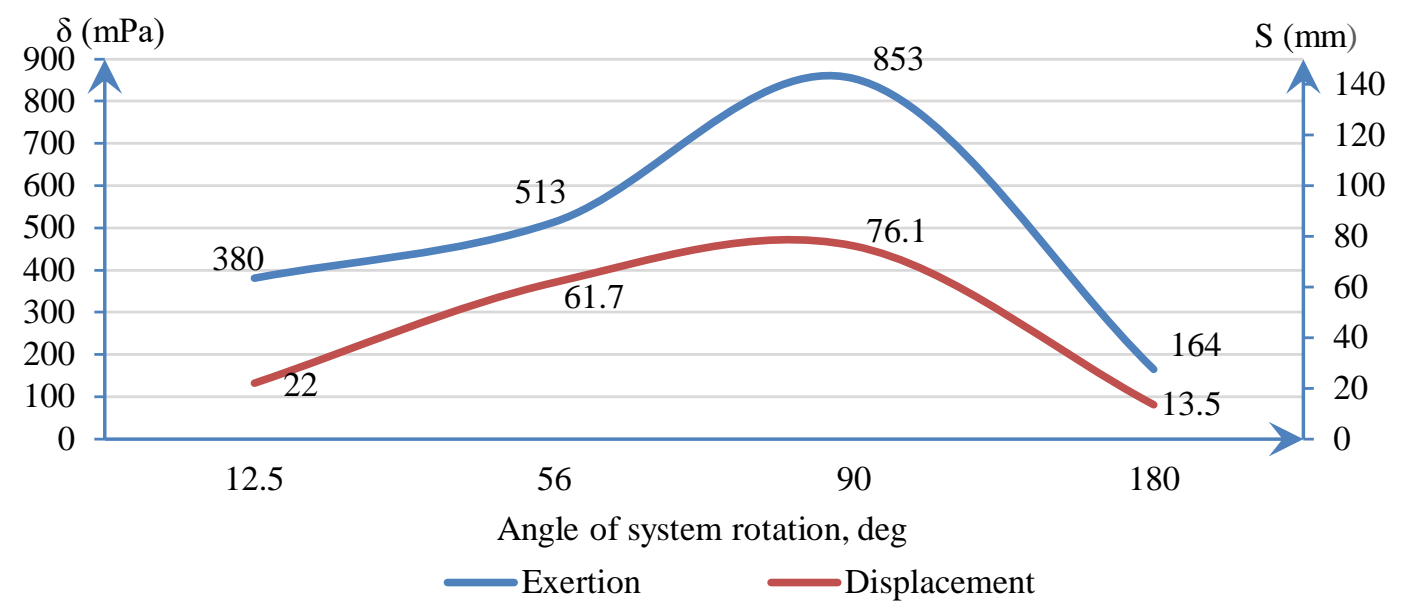

Figure 5. Dependence of stresses and displacements in the average span of the side wall on the angle of rotation of the cur dumper platform

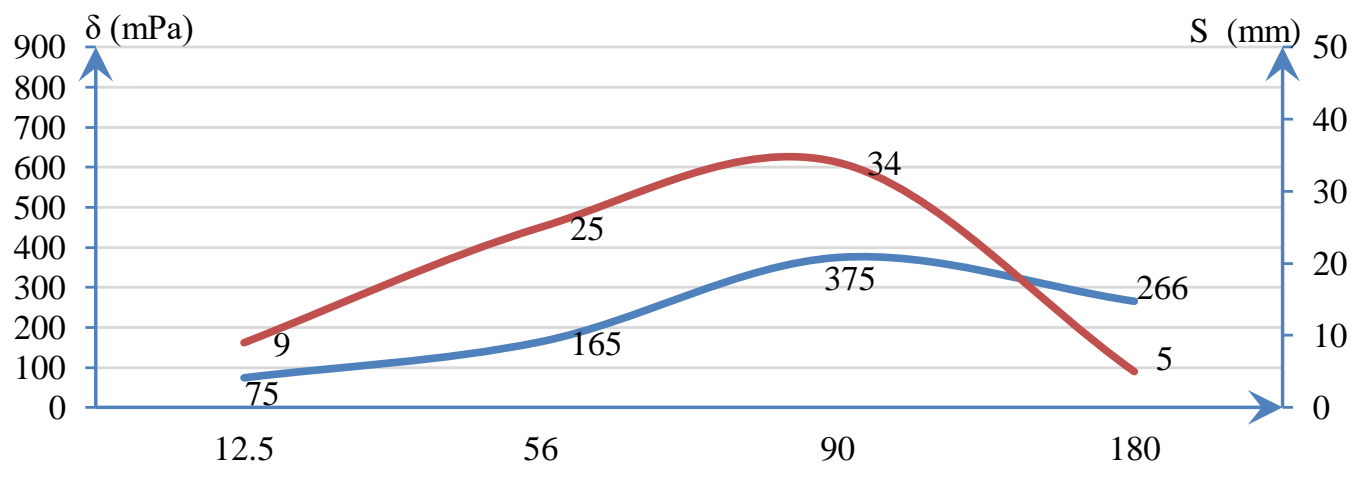

Angle of system rotation, deg .

Exterion Displacement

Figure 6. Dependence of stresses and displacements in the car body frame on the angle of rotation of the cur dumper platform

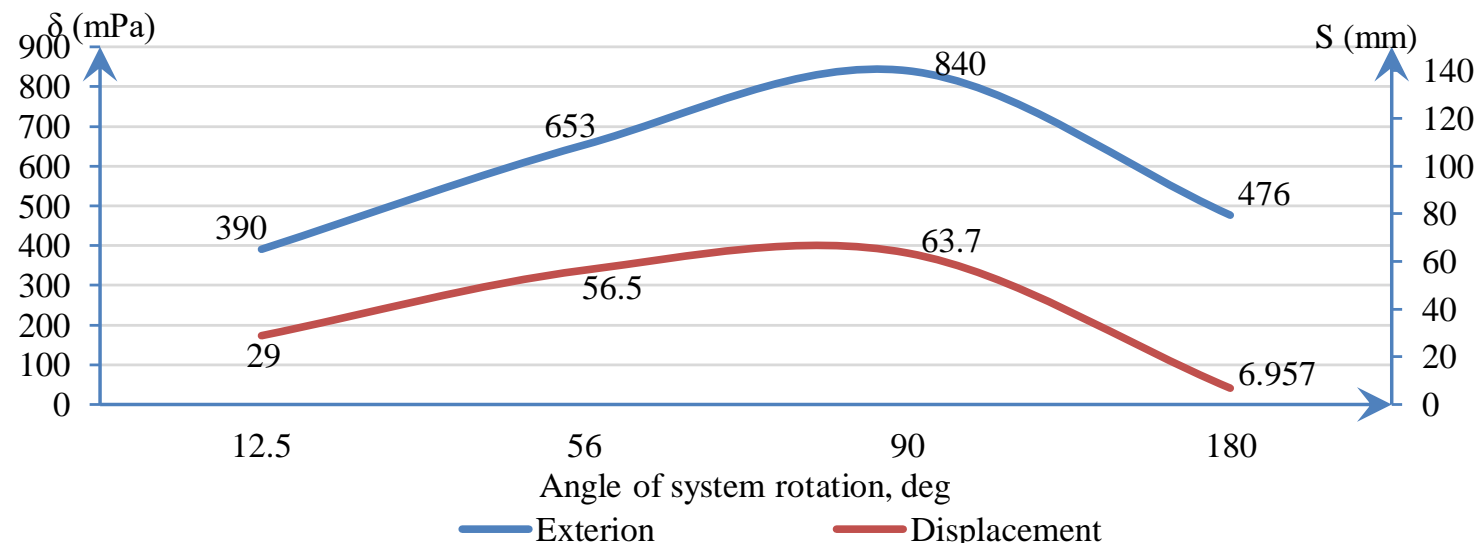


Figure 7. The dependence of stresses and displacements in the end span of the side wall of the body on the angle of rotation of the cur dumper platform

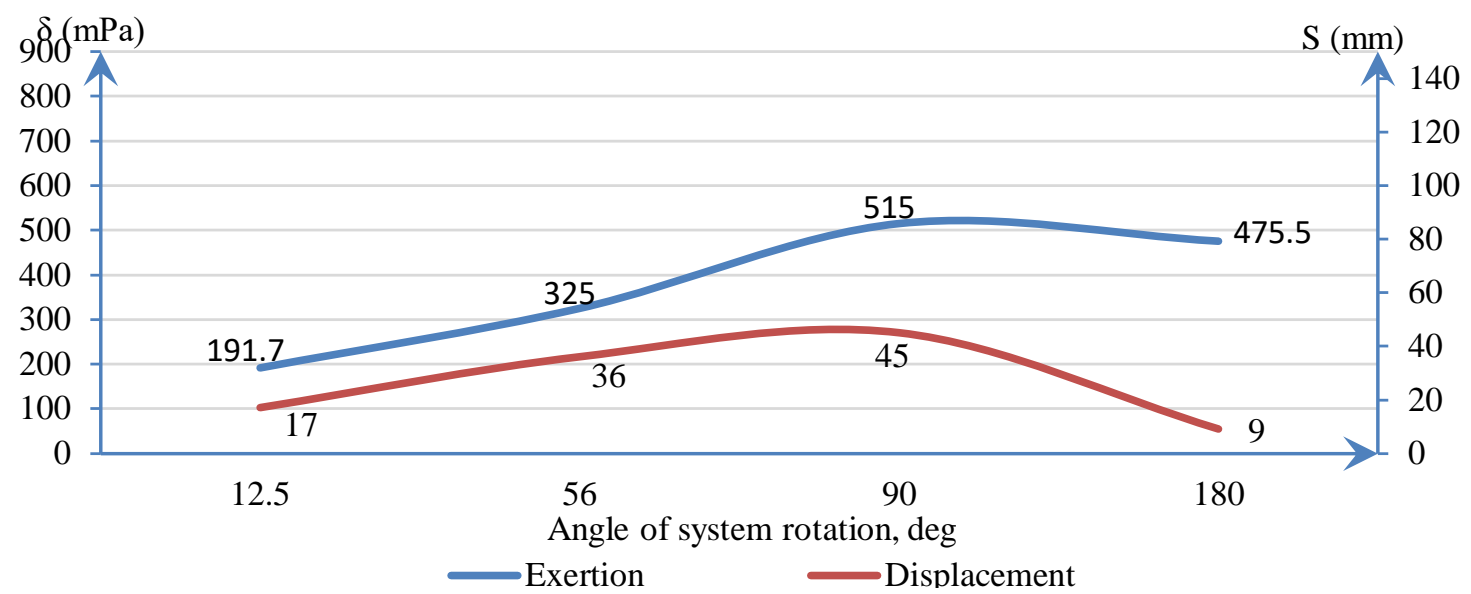

Figure 8. Dependence of stresses and displacements in the carriage body top cord during unloading on the rotary car dumper

\section{CONCLUSIONS}

Studies are aimed at ensuring the safety and operational reliability of freight cars. The safety of the freight car fleet in places of intensive loading and unloading of mass bulk cargo can be ensured only when unloading by car dumper technique. The most common device for such unloading is a rotary car dumper. The damage to the cars during unloading depends on the technical condition and design of this car dumper.

The analysis of developments in this area showed that when constructing the design scheme of the dynamic interaction of the car with the car dumper, external factors were not taken into account. These factors are violation of the interaction geometry, design features of the car dumper and the car.

Studies of the stress-strain state of the car during unloading, analysis of the resulting loads shown that at different angles of rotation, loads exceeding the safety margin of the body components can affect the loadbearing structure elements. A mathematical model of the stress-strain state of the car body was developed, calculations of stresses and displacements were performed, which showed that the existing standard safety margin of the body elements might not be sufficient to ensure the operational reliability and safety of the carriages.

The results of the development can be used in the design of freight cars bodies of a new generation with the strengthening of the load-bearing structure of the body. In addition, their use is advisable when improving the design of car dumpers to adapt to the parameters of the bodies of unloaded cars.

\section{REFERENCES}

Azab, A., Karam, A., Eltawil, A. (2020). A simulation-based optimization approach for external trucks appointment scheduling in container terminals. International Journal of Simulation Modelling 40, 321328. 
Chepurchenko I.V., Nosyrev D.Ya., Korkina, S.V., Anakhova, M.V. (2019). Direction of improvement of the deep-wagon gondola for the transportation of bulk cargo. Vestnik Transporta Povolzhya 1, 28-35.

Chepurchenko, I.V., Nosyrev, D.Ya., Kroshechkina, I.Yu. (2018). Analysis of the reliability of gondola car body structures in operation. Science and Technology in Transport 4, 34-40.

Chepurnoy, A.D., Sheichenko, R.I., Graborov, R.V., Tkachuk, N.A., Bondarenko, N.A., Grabovsky, A.V., Luniov, E.A. (2017). Numerical research into freight car. Journal of NTU KhPI 23, 47-55.

Dižo, J., Steišunas, S., Blatnický, M. (2016). Simulation analysis of the effects of a rail vehicle running with wheel flat. Manufacturing Technology 16, 889-896.

Gorbunov, M., Pistek, V., Kovtanets, M., Nozhenko, O., Kara, S., Kučera, P. (2017). Research to improve traction and dynamic quality of locomotives. Ibroengineering Procedia 13, 159-164.

Gorfin, O.S. (2003). Machinery and equipment for processing peat. Tver: Tver State Technical University.

Kostek, R., Aleksandrowicz, P. (2017). Simulation of car collision with an impact block. IOP Conference Series: Materials Science and Engineering 252, 012008.

Nosyrev, D.Ya., Chepurchenko, I.V., Korkina, S.V. (2018a). Determination of inertial dynamic loads acting on the body of a gondola car when unloading on a rotary tipping car. Transport of the Urals 4(59), 63-67.

Nosyrev, D.Ya., Chepurchenko, I.V., Korkina, S.V. (2018b). Using the theory of optimal design for improving the design of the deep-wagon gondola. Vestnik Transporta Povolzhya 3, 28-32.

Petrov, G.I., Chepurchenko, I.V., Panachev, O.I., Petrov, G.I. (2017). Adaptation of the mathematical model of a gondola car to the conditions of unloading the body by the tipping method. Transport business of Russia 1(128), 138-142.

Scientific Research Institute of Railway Transport. (2016). Freight Wagons. Strength and Dynamic Quality Requirements: GOST 33211-2014 2014, http://docs.cntd.ru/document/1200121493, last accessed 2021/03/21.

Senderov, G.K., Losev, P.R., Drugal, S.A. (1984). Safety of the wagons during loading and unloading and shunting works. Transport, Moscow. 